\title{
MODELING A HUMANITARIAN LOGISTICS INFORMATION SYSTEM'S PROCESSES AND INFORMATION NEEDS
}

\author{
Dimitris Folinas ${ }^{1}$, Dimitris Aidonis ${ }^{2}$, Charis Achillas ${ }^{3}$ \\ 1,2,3 Department of Supply Chain Management, International Hellenic University, Greece
}

Received 15 March 2019; accepted 12 April 2019

\begin{abstract}
The purpose of this paper is to model the user requirements for an information system for the management of logistics processes of a humanitarian supply chain. The modeling procedure includes the development of the physical architecture as well as UML Diagrams. UML (Unified Modeling Language) is a standard language for specifying, visualizing, constructing, and documenting the artifacts of software systems.
\end{abstract}

Keywords: humanitarian supply chain, relief logistics, logistics information management systems, information systems modeling.

\section{Introduction}

Humanitarian Logistics Management is the process of designing, implementing and controlling efficient / efficient product flow and storage, as well as, relevant information, from the point of origin to the point of consumption, in order to relieve people suffering after a disaster or disorder that affects the operation of a system causing extensive human, material, and environmental damage). In times of these disasters or disorders, the need for accurate and timely information is as crucial as is a rapid and coherent coordination among the international humanitarian community (European Commission, 2007).

Humanitarian Logistics Information Systems (HLIS) have the potential to enable better information sharing between organizations which can enhance the overall humanitarian operation (King, 2005). Effective humanitarian information systems that provide timely access to comprehensive, relevant and reliable information are critical to humanitarian operations (Balcik et al., 2010).

The purpose of this paper is to model the key functionalities of a HLIS for the management of logistics processes of a humanitarian supply chain. The modeling procedure includes the identification of user requirements and the main modules, and the development of Unified Modeling Language (UML) diagrams. The information system under review is the main deliverable of the research program entitled: Integrated Operations Center for Providing Humanitarian Assistance (HELP), financed by the INTERREG IPA Cross Border Cooperation Program "Greece - FYROM 2014-2020”.

HELP's main objective is the development of two (2) container business centers (a Command Center - C4I Mobile Container

${ }^{1}$ Corresponding author: folinasd@teicm.gr 
and a MEDICAL Treatment Container) to better coordinate and support logistics processes in the case of humanitarian aid. In other words to provide the right supplies to the right place, to the right people, the right time and the right amount as well as to coordinate and manage the resources available, provide a reliable business image and support decision-making.

\section{HLIS's Key Parameters}

The examined system will accept a wide variety of input data from various sources such as, from: human resources, materials' status, monitoring the allocation and use of resources, logistics equipment and tools, telecommunication tools and platforms, tracking and motion detection systems, external events, etc., in order to disseminate via internet and present in a user-friendly format -in two-dimensional and threedimensional- maps critical information needed to support the decision-making process.

The HLIS will have the ability to archive all aspects of a created events / incidents, so it becomes a powerful and adaptable tool for analyzing any response. Furthermore, whatif scenarios, statistics and reports will be easily generated and shared, that can impact future response planning and execution. As such, it has tremendous utility across all echelons: tactical, operational, and strategic.

According to "Global Symposium +5 ", the principles of humanitarian information systems are the following:
- Accessibility. Hum anitarian information and data should be made accessible to all humanitarian actors by applying easy-to-use formats and by translating information into common or local languages. Information and data for humanitarian purposes should be made widely available through a variety of online and offline distribution channels including the media.

- Inclusiveness. Information management and exchange should be based on collaboration, partnership and sharing with a high degree of participation and ownership by multiple stakeholders including national and local governments, and especially affected communities whose information needs should equally be taken into account.

- Inter-operability. All sharable data and information should be made available in formats that can be easily retrieved, shared and used by humanitarian organizations.

- Accountability. Information providers should be responsible to their partners and stakeholders for the content they publish and disseminate.

- Verifiability. Information should be accurate, consistent and based on sound methodologies, validated by external sources, and analyzed within the proper contextual framework.

- Relevance. Information should be practical, flexible, responsive, and 
driven by operational needs in support of decision-making throughout all phases of a crisis. Data that is not relevant should not be collected.

- Impartiality. Information managers should consult a variety of sources when collecting and analyzing information so as to provide varied and balanced perspectives for addressing problems and recommending solutions.

- Humanity. Information should never be used to distort, to mislead or to cause harm to affected or at risk populations and should respect the dignity of victims.

- Timeliness. Humanitarian information should be collected, analyzed and disseminated efficiently, and must be kept current.

- Sustainability. Humanitarian information and data should be preserved, cataloged and archived, so that it can be retrieved for future use, such as for preparedness, analysis, lessons learned and evaluation. The use of Open Source Software should be promoted to further enhance access to information by all stakeholders in a sustainable way. When possible, post emergency data should be transitioned to relevant recovery actors and host governments.
- Reliability. Users must be able to evaluate the reliability and credibility of data and information by knowing its source and method of collection. Collection methods should adhere to global standards where they exist to support and reinforce credibility. Reliability is a prerequisite for ensuring validity and verifiability.

- Reciprocity. Information exchange should be a beneficial two-way process between the affected communities and the humanitarian community, including affected governments.

- Confidentiality. The processing of any personal data shall not be done without the prior explicit description of its purpose and will only be done for that purpose, and after prior informed consent of the individual concerned. Sufficient safeguards must be put in place to protect personal data against loss, unauthorized processing and other misuse. If sensitive information is publicly disclosed, the sources of such information will not be released when there is a reasonable risk that doing so will affect the security or integrity of these sources.

Moreover, the following table presents the functional requirements that the managers of the sample identify and assess:. 


\section{Table 1}

Classification and Categorization of Functional Requirement

\begin{tabular}{|c|c|}
\hline \multirow{6}{*}{ A } & Assigning resources to disasters and dealing with emergencies. \\
\hline & Provide operational status to all parties involved. \\
\hline & Tracking and tracing of logistics equipment and tools. \\
\hline & Telecommunication services (local and cloud). \\
\hline & Tracking and motion detection systems (CCTV, detectors, sensors, alarms, etc.). \\
\hline & Telecommunication platforms (fixed, satellite, GSM, radio, internet). \\
\hline \multirow{10}{*}{ B } & Real-time reporting on the state of road networks. \\
\hline & Event management (display, import, modification, deletion). \\
\hline & Show events on a digital map. \\
\hline & Ability to present information to mobile phones. \\
\hline & Provide all the information needed to support the decision-making process. \\
\hline & Save event-related information in a digital geographic database. \\
\hline & Ability and recording of business "what-if" scenarios. \\
\hline & Ability to send individual and mass messages. \\
\hline & Compatibility and integration with automated object recognition technologies (barcodes, RFID, etc.). \\
\hline & Creating and managing disaster scenarios. \\
\hline \multirow{9}{*}{$\mathbf{C}$} & Manage communication and exchange of standardized messages. \\
\hline & Present availability and operational status of available resources. \\
\hline & $\begin{array}{l}\text { Creation and management of business scenarios that are linked to the occurrence of natural disaster events } \\
\text { or general events requiring the activation and support of decisions of the humanitarian logistics system. }\end{array}$ \\
\hline & Providing real-time information on the state of the materials. \\
\hline & Dynamic resource sharing. \\
\hline & Display scenarios on a digital map by retrieving data from the database. \\
\hline & Providing real-time information on the operational status of logistics equipment and tools. \\
\hline & Presentation of geographic data in two-dimensional and three-dimensional maps. \\
\hline & Monitoring the allocation and use of resources. \\
\hline
\end{tabular}

The discussion of the proposed system includes the identification of the modules, the description of the architecture and the key roles.

\subsection{HLIS Modules}

The information system's functionalities reference model consists of eight (8) modules as presented below:

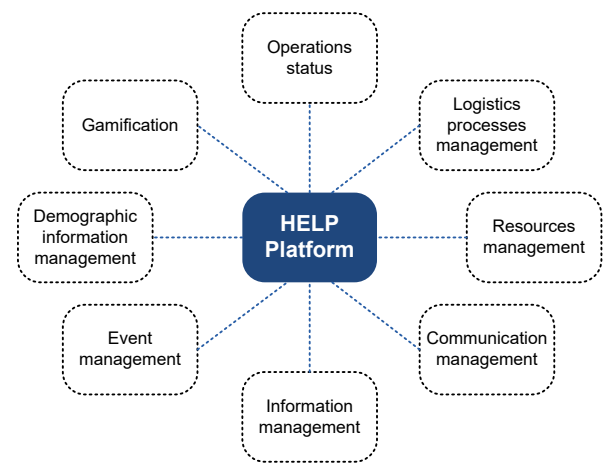

Fig. 1.

Information System's Functionalities Reference Model 
The modules and the corresponding functionalities are presented in the following table:

\section{Table 2}

Functional Requirements of a HLIS of a Humanitarian Supply Chain

\begin{tabular}{|c|c|}
\hline Module & Functionalities \\
\hline Operational status & $\begin{array}{l}\text { - Create and deliver to all the involved parties the business image in real time and on a } \\
\text { digital map. } \\
\text { Visualize (locate and detect) logistics infrastructure locations and provide additional } \\
\text { operational status information of available resources and materials. }\end{array}$ \\
\hline $\begin{array}{l}\text { Logistics processes } \\
\text { management }\end{array}$ & $\begin{array}{l}\text { Maintaining a supplier database and continually updating it, as well as, continuing } \\
\text { training suppliers on how to act in a period of crisis to meet the required standards. } \\
\text { Selection of a route to optimize transport and distribution either direct (direct - direct } \\
\text { transfer from the distribution center to the affected concentration points or indirect } \\
\text { transfer via intermediate distribution centers). } \\
\text { Monitoring (for example, the knowledge of the location of the material in the supply } \\
\text { chain - where it is located) and tracking (inventory of the previous points - how did it } \\
\text { arrive?) of the materials. } \\
\text { - Store and manage inventory for the immediate and satisfactory response to a disaster. }\end{array}$ \\
\hline $\begin{array}{c}\text { Resources } \\
\text { management }\end{array}$ & $\begin{array}{l}\text { - Inform about the availability and operational status of resources (such as water or food } \\
\text { for immediate transport to the affected). } \\
\text { - } \quad \text { Assign resources to disasters and incidents. } \\
\text { - } \quad \text { Donitoring Assignment / Use of Resources. } \\
\text { - } \quad \text { Ability to interface with automated (auto) object recognition technologies (barcodes, } \\
\text { QR codes, RFID). }\end{array}$ \\
\hline $\begin{array}{l}\text { Communications } \\
\text { management }\end{array}$ & $\begin{array}{ll}\text { - } & \text { Telecommunication services (local, cloud). } \\
\text { - } & \text { Telecommunication platforms (fixed, satellite, GSM, radio, internet). } \\
\text { - } & \text { Integrated monitoring systems (CCTV, detectors, sensors, alarms, etc.). }\end{array}$ \\
\hline $\begin{array}{l}\text { Information } \\
\text { management }\end{array}$ & $\begin{array}{l}\text { - } \quad \text { Provide all the information needed to support the decision-making process. } \\
\text { - } \quad \text { Geographic information system (GIS) capable of displaying 2D \& 3D digital maps. } \\
\text { - } \quad \text { Managing online communication and information exchange in the form of standardized } \\
\text { messages. } \\
\text { Bulk or individual sending of messages. }\end{array}$ \\
\hline Event management & $\begin{array}{l}\text { Creation of a new event (real-time or delayed), and their management (modification, } \\
\text { deletion, etc.). } \\
\text { Link an event to the digital map and: } \\
\text { o indicating an event on a digital map (Google maps, etc.). } \\
\text { o storing event-related information in a geographic digital information database. } \\
\text { - recovery from this base. } \\
\text { Update real-time event display on Android, IoS, or Windows mobile devices, and } \\
\text { Internet browsers, and retrieve information from the Geographic Digital Information } \\
\text { Database. }\end{array}$ \\
\hline $\begin{array}{l}\text { Manage basic } \\
\text { demographic } \\
\text { information }\end{array}$ & $\begin{array}{l}\text { Example of grouping information include: age grouping, by region, other statistics - } \\
\text { aggregated demographic data. }\end{array}$ \\
\hline Gamification & $\begin{array}{l}\text { - Creation and management of business scenarios that are linked to the occurrence } \\
\text { of natural disaster events or general events requiring the activation and support of } \\
\text { decisions of the humanitarian logistics system. } \\
\text { - Display scenarios on a digital map by retrieving data from the geographic digital } \\
\text { information database. } \\
\text { - } \quad \text { Ability to record and maintain business what-if scenarios. } \\
\text { Manage scenario reports (predefined - adhoc). }\end{array}$ \\
\hline
\end{tabular}




\subsection{Architecture}

The above system will be a Command and Control (C2) architecture of at least 3 levels of multi-level architecture (Web n-tier):

- Client tier / presentation tier / User Interaction will refer to the end-user interface and the presentation of the data. User access to the services available will be through a single technology platform, which will provide the user with identification, personalization and authorized access capabilities.

- The application / business logic tier application layer, which integrates business logic, that is, all business rules that govern the operation of each application.

- The data tier, which is responsible for storing data. It concerns information storage and management systems, whether it concerns transactional data, master data, or aggregate data. Application layer subsystems should be able to share common data models and shared data infrastructure.

\subsection{Roles}

The final users (actors) of the proposed HLIS are:

- System Administrator: This is the role reserved for MIS administrator.

- GIS Administrator: This is an individual that works with GIS databases and has been assigned the duties of uploading data layers as appropriate for given incidents as well as general use.

- Organization Administrator: This is the individual (or group of individuals) that manages that organization's membership in MIS, keeps contact information upto-date, and supervises orientation and training of MIS. Potential organizations are the following key target groups of users of the proposed MIS:

o Different levels of Civil Protection;

o Representatives of all the local, regional, and municipal authorities in the eligible areas;

o Army;

o Fire Department;

o Emergency medical centers;

- Local, regional, national, European, but also specialized mass-media, which contribute to the promotion of the Programme in the eligible areas;

o Civil Protection and Crisis management policy makers.

- Field team leaders: Individuals or group of individuals that gather, insert operational information and share information with others.

\section{UML Diagrams}

The purpose of this paper is to model the user requirements for an information system for the management of logistics processes of a humanitarian supply chain. The modeling procedure includes the development of UML Diagrams. The Unified Modeling Language is a language for specifying, constructing, visualizing, and documenting the artifacts of a software-intensive system. Analogous to the use of architectural blueprints in the construction industry, UML provides a common language for describing software models, and it can be used in conjunction with a wide range of software lifecycles and development processes (Booch et al., 1999; Rosenberg and Scott, 1999; Schneiderand, 1998). Two types of UML diagrams will be developed in this report:

- Use Case Diagrams, and

- Sequence Diagrams. 


\subsection{Use Case Diagrams}

First, for each role that have been identified in the previous section, a use case diagram is developed to illustrate the functionalities of the

System Administrator:

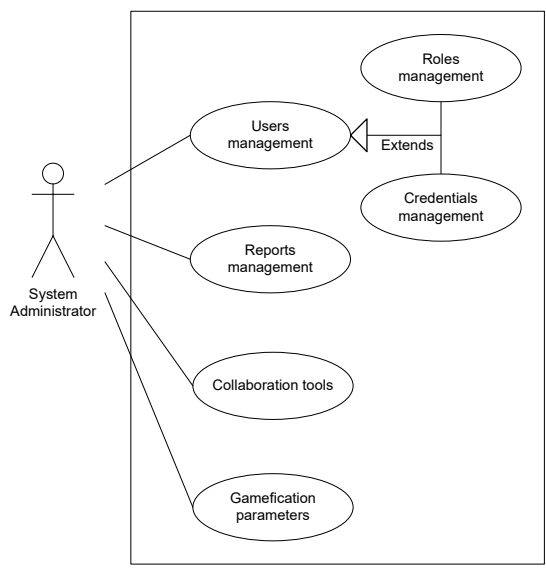

Organization Administrator:

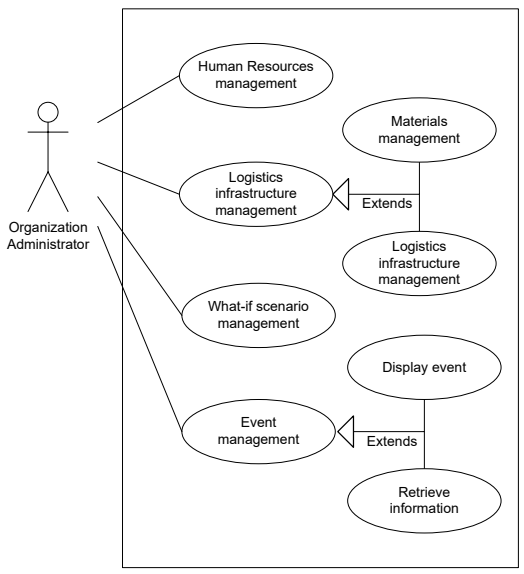

Fig. 2.

Use Cases of HLIS proposed system. Use case diagrams are referred to as behavior diagrams used to describe a set of actions (use cases) that the proposed HLIS should or can perform in collaboration with one or more external users of the system (actors).

\section{GIS Administrator:}

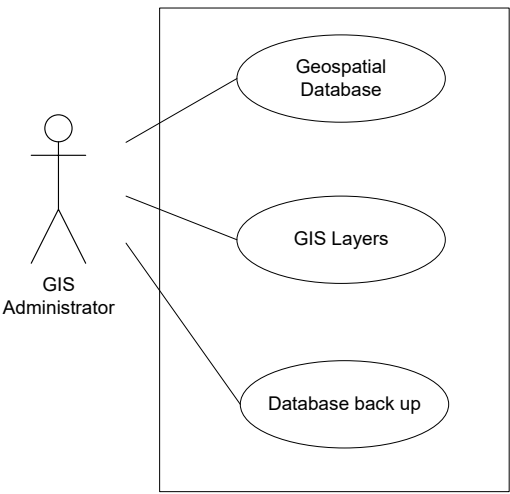

Field team leaders:

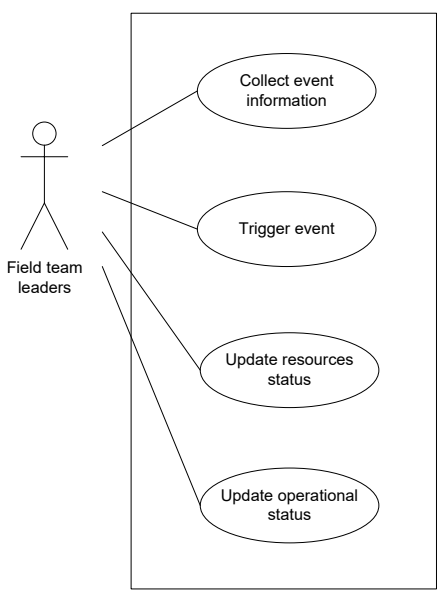




\subsection{UML Sequence Diagrams}

Moreover, a sequence diagram that involves three of the four roles is provided below to describe interactions among them in terms of an exchange of messages over time and to visualize and validate the event handling scenario.

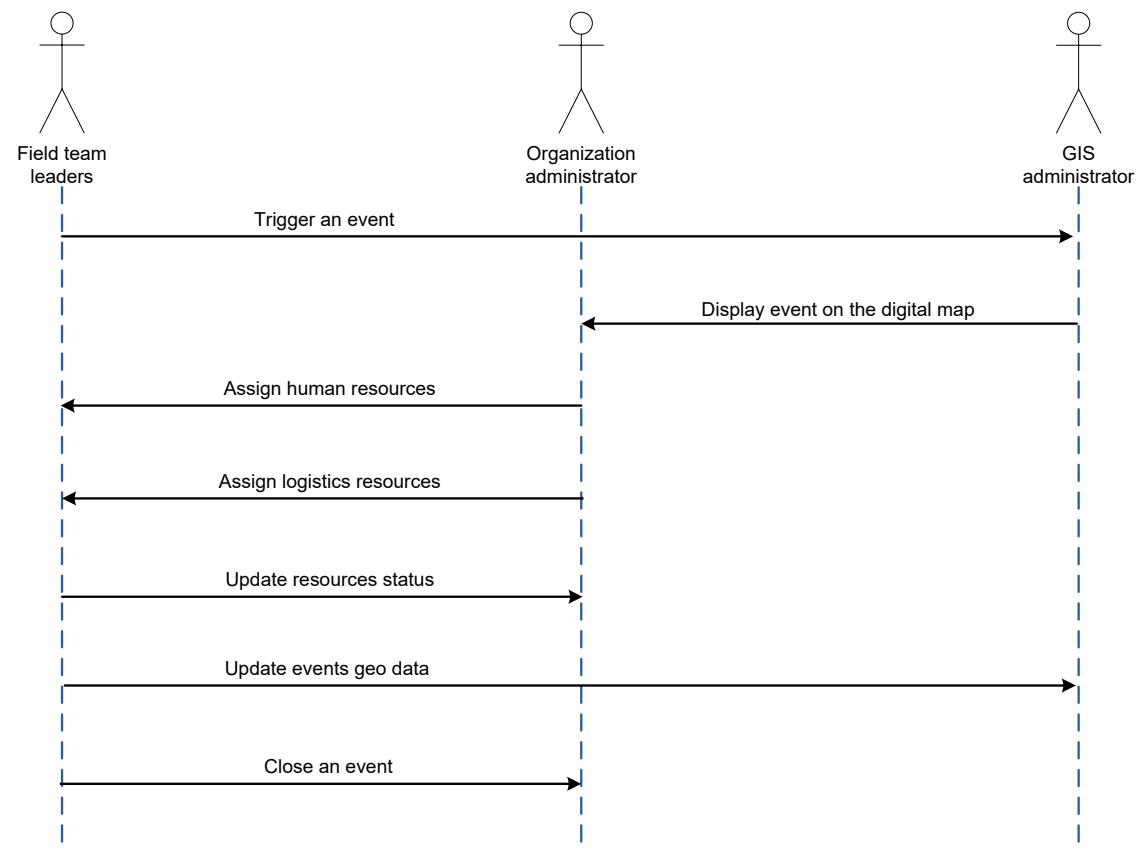

Fig. 3.

HLIS Sequence Diagram

\section{Conclusions}

As reported in the Pamela Steele Associates Ltd (PSA) report entitled "Humanitarian supply chain information systems: insights for successful implementation", although each of the parties involved in a humanitarian supply chain uses innovative IT and telecommunication solutions, solutions have not been developed will coordinate these members (PSA, 2015). One reason for this paradoxical phenomenon is the fact that supply chains are still not seen as a critical success factor in a humanitarian aid program (Blansjaar and van der Merwe, 2011).
In recent years, several technological solutions have been developed, such as Helios IP funded by the renowned Fritz Institute. This system has been adopted by major humanitarian organizations such as Save the Children International, World Vision International and Care USA (Blansjaar and van der Merwe, 2011). However, the cost of purchasing and maintaining such a solution is very high especially for the regions that will support the HELP project. An appreciation of the project team is the acquisition of a more flexible and economical technological solution. 
Functional requirements capture the intended behavior of the examined HLIS system. This behavior for the focused MIS for the humanitarian logistics system may be expressed as services, tasks or functions the system is required to perform. Use cases are useful in capturing and communicating functional requirements, and as such they play a primary role in product definition. An architecturally relevant subset of the use cases for each of the products to be based on the architecture also plays a valuable role in architecting. They direct the architects to support the required functionality, and provide the starting points for sequence diagrams that are helpful in component interface design and architecture validation.

\section{Acknowledgements}

This research was supported by the Interreg IPA Cross Border Cooperation Programme CCI 2014 TC 16 I5CB 009, which is co-funded by the European Union and by National Funds of the participating countries, under the Subsidy Contract No. 19 for the project entitled "Integrated Operations Center for Providing Humanitarian Assistance” (HELP).

\section{References}

Balcik, B.; Beamon, B.M.; Krejci, C.C.; Muramatsu, K.M.; Ramirez, M. 2010. Coordination in humanitarian relief chains: practices, challenges and opportunities, International Journal of Production Economics 126(1): 22-34.

Blansjaar, M.; van der Merwe, C. 2011. The Importance of Information Technology in Humanitarian Supply Chains: Opportunities and Challenges in the Helios
Project. In: Christopher., M., Tatham, P. eds. 2011. Humanitarian Logistics: Meeting the Challenge of Preparing for and Responding to Disasters. London; Philadelphia. Kogan Page: 47-64.

Booch, G.; Jacobson, I.; Rumbaugh, J. 1999. The Unified Modeling Language User Guide. Addison-Wesley, 219-241.

European Commission. 2007. Strengthening humanitarian information systems essential to the coordination of humanitarian assistance through thematic support to the United Nations Office for the Coordination of Humanitarian Affairs (OCHA). Report from European Commission's Directorate-General for European Civil Protection and Humanitarian Aid Operations, Published on 27 Feb 2006 [online], Available from internet: < https://reliefweb.int/ report/world/strengthening-umanitarian-informationsystems-essential-coordination-humanitarian $>$.

Global Symposium +5. 2007. Information for Humanitarian Action, Survey Report, [online], Available from internet: <http://www.cdacnetwork. org/contentAsset/raw-data/25414395-9c91-4e59-94b26af0b7a2d35a/attachedFile>.

King, D. 2005. Humanitarian Knowledge Management. In Proceedings of the Second International ISCRAM Conference, Brussels, Belgium: 1-6.

PSA. 2015. Humanitarian supply chain information systems: insights for successful implementation (White paper). [pdf] Pamela Steele Associates Ltd. Available from internet: <https://www.pamsteele.co.uk/wpcontent/uploads/2018/08/PSA-Humlog-IT-WP.pdf >.

Rosenberg, D.; Scott, K. 1999. Use Case Driven Object Modeling with UML. Addison-Wesley.

Schneider, G.; Winters, J. 1998. Applying Use Cases: A Practical Guide. Addison-Wesley. 